\title{
Exploring Human Longevity: The Impact of Climate on Life Expectancy
}

\author{
Riya Kewalani, Insiya Sajjad Hussain Saifudeen \\ Dubai Gem Private School, Oud Metha Road, Dubai, PO Box 989, United Arab Emirates; riya.insiya@gmail.com
}

ABSTRACT: This research aims to investigate whether climate has an impact on life expectancy. In analyzing economic data from 172 countries that are publicly available from the United Nations World Economic Situation and Prospects 2019, as well as classifying all countries from different regions into hot or cold climate categories, the authors were able to single out income, education, sanitation, healthcare, ethnicity, and diet as constant factors to objectively quantify life expectancy. By measuring life expectancies as indicated by the climate, a comprehensible correlation can be built of whether the climate plays a vital role in prolonging human life expectancy and which type of climate would best support human life. Information gathered and analyzed from examination focused on the contention that human life expectancy can be increased living in colder regions. According to the research, an individual is likely to live an extra 2.2163 years in colder regions solely based on the country's income status and climate, while completely ruling out genetics.

KEYWORDS: Earth and Environmental Sciences; Life expectancy; Climate Science; Longevity; Income groups.

\section{Introduction}

To better understand the study, it is crucial to understand the difference between life span, life expectancy, and longevity. According to the United Nations Population Division, life expectancy at birth is defined as "the average number of years that a newborn could expect to live if he or she were to pass through life subject to the age-specific mortality rates of a given period." ${ }^{1}$ When addressing the life expectancy of a country, it refers to the mean life span of the populace in that country. This factual normal is determined dependent on a populace in general, including the individuals who die during labor, soon after labor, during puberty or adulthood, the individuals who die in war, and the individuals who live well into mature age. On the other hand, according to News Medical Life Sciences, life span refers to "the maximum number of years that a person can expect to live based on the greatest number of years anyone from the same data set has lived." ${ }^{2}$ Taking humans as the model, the oldest recorded age attained by any living individual is 122 years, thereby implicating that human beings have a lifespan of at least 122 years. Life span is also known as longevity.

As life expectancy has been extended, factors that affect it have been substantially debated. Consensus on factors that influence life expectancy include gender, ethnicity, pollution, climate change, literacy rate, healthcare access, and income level. Other changeable lifestyle factors also have an impact on life expectancy, including but not limited to, exercise, alcohol, smoking and diet. Nevertheless, life expectancy has for the most part continuously increased over time.

The authors' study aims to quantify and study the factors that affect human life expectancy. According to the American Journal of Physical Anthropology, Neolithic and Bronze Age data collected suggests life expectancy was an average of 36 years for both men and women. ${ }^{3}$ Hunter-gatherers had a higher life expectancy than farmers as agriculture was not common yet and people would resort to hunting and foraging food for survival. From then, life expectancy has been shown to be an upward trend, with most studies suggesting that by the late medieval English era, life expectancy of an aristocrat could be as much as 64 years; a figure that closely resembles the life expectancy of many populations around the world today. The increase in life expectancy is attributed to the advancements made in sanitation, education, and lodging during the nineteenth and mid-twentieth centuries, causing a consistent decrease in early and midlife mortality. Additionally, great progress made in numerous regions of well-being and health, such as the discovery of antibiotics, the green revolution that increased agricultural production, the enhancement of maternal and child survival, and mortality from infectious diseases, particularly human immunodeficiency virus (HIV)/ AIDS, tuberculosis (TB), malaria, and neglected tropical diseases (NTDs), has declined. According to the World Health Organization (WHO), global average life expectancy has increased by 5.5 years between 2000 and 2016, which has been notably the fastest increase since the 1950s. ${ }^{4}$ As per the United Nations World Population Prospects, life expectancy will continue to display an upward trend in all regions of the world. However, the average life expectancy isn't predicted to grow exponentially as it has these past few decades. Projected increases in life expectancy in Northern America, Europe and Latin American and the Caribbean are expected to become more gradual and stagnant, while projections for Africa continue at a much higher rate compared to the rest of the world. Asia is expected to match the global average by the year 2050. Differences in life expectancy across regions of the world are estimated to persist even into the future due to the differences in group incomes, however, income disparity between regions is forecasted to diminish significantly by 2050 (Figure 1). ${ }^{5}$ 


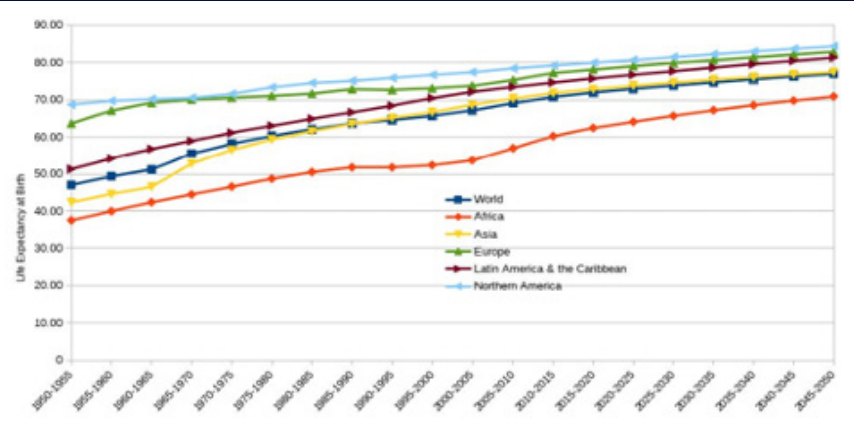

Figure 1: Trend line of life expectancy from 1950 to 2050 by world regions. Source: Life Expectancy by Region from UN World Population Prospects. The graph illustrates exact increases in life expectancy until 2017, and then predicts trends to 2050 .

The blue zone areas (Figure 2) are five regions across the world, identified as 'the hot spots of longevity' according to National Geographic, where people live much longer than average. ${ }^{6}$ All of these cities house a population where many individuals hit the 100 years milestone. When the authors encountered "blue zone" areas in multiple studies about factors affecting human longevity, the authors observed a pattern in the placement of these blue zone areas on the world map-they are all located from 1100 to $4500 \mathrm{~km}$ north of the equator, and all experience Mediterranean or tropical climates, or what the authors classified as 'warm' in accordance with the designed classification system. The factors attributed to the longer life spans of these communities are healthy diet, daily exercise, and adopting a low-stress lifestyle. However, in no study has climate ever been mentioned as a contributing factor to extending life span in these blue zone areas, when they so clearly have warm and coastal climates as a common factor. This got the authors thinking: does climate play a role in or affect human life expectancy? Scientists have debated the role of climate and temperature in human longevity for decades. On first glance, and while considering blue zone areas, it could be suggested that humans live longer on average in warmer climates. This side of the argument is supported by multiple studies, such as one by Professor F. Ellis of Yale University, who found that deaths in the United States increased by $13 \%$ in the winter, compared to the summer, using data from the 1950s. ${ }^{7}$ The opposite side of the debate claims that living in colder climates slows down ageing and thus extends life expectancy. The principal theory corroborating this side of the debate is the 'free radical theory' that states organisms age because of buildup in cells and damage from metabolic activities, in particular, a byproduct under the name reactive oxidative species (ROS). The theory claims that exposure to colder temperatures slows down the rate of ageing-thus slowing the release of the byproduct ROS so that less cellular damage occurs over time and thereby slowing ageing and increasing life expectancy. ${ }^{8}$

The authors' aim with this study was to investigate how rising and warmer temperatures will affect human life expectancy and longevity, which is where climate change comes into play. According to the International Actuarial Association, climate change has already demonstrated that it will have critical and extensive impacts around the globe. ${ }^{10}$ The most significant objective for this paper was the mortality of the populace. Climate change is enduring danger to our planet. Largely, this will result from critical rises in $\mathrm{CO}_{2}$ and methane levels in the Earth's atmosphere, environment, and oceans that have been amassing through many decades. This risk will unfavorably influence our water, air, climate, and ecosystems, bringing about numerous changes to our environment, including augmentations in temperature, changes in precipitation, for example, heavy rains and longer-enduring droughts, a rise of infrequent extreme weather, as well as sea and ocean levels. A definitive impact of these climatic changes will influence human wellbeing, life, and property. Be that as it may, the degree of climate change remains a present-day and grave future dilemma.

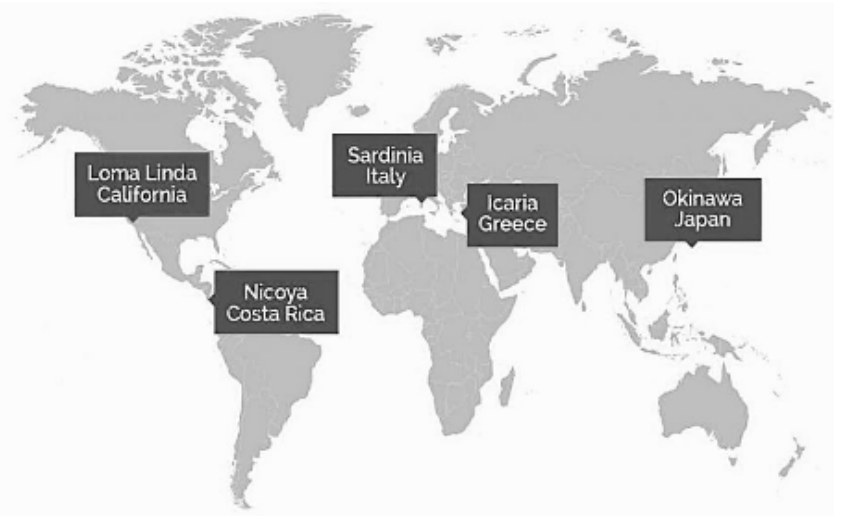

Figure 2: Cities that form the 'blue zone' areas on the world map.9.

Acknowledging the arguments from both sides of the debate, and having read, analyzed and reviewed the literature available on this topic, the authors set out to quantify any impacts climate has on longevity. By quantifying life expectancy according to climate, a clear correlation can be established of whether climate plays an integral role in human longevity and which type of climate best supports human life. Data collected and examined from the research points towards the argument that human life expectancy can be extended by living in colder climates. Colder climates overwhelmingly display higher life expectancy in all four socio-economic country classifications.

\section{Methods}

The countries of the world were classified initially based on four income groups: high income, upper-middle-income, lower-middle-income, and low income. These classifications were taken directly from the United Nations World Economic Situation and Prospects 2019 Country Classification. ${ }^{12}$ Following this, the authors further classified the countries in each income group as 'mainly warm' and 'mainly cold' (Figure 3). This closed question approach was critical to establish a correlational link between climates, temperature, and human life expectancy. Countries with mainly tropical, subtropical, sub-Saharan, Mediterranean, savanna, and equatorial climates were classified under warm. These countries have dry, arid, hot, and humid temperatures with rainy winters and saw almost no winters with freezing temperatures. Countries with more seasonal climates, temperate, continental, oceanic, maritime, and 
highland climates were grouped under cold. Classifying countries based on income groups was essential to keep climate a constant factor as far as possible because income directly affects access to education, sanitation, access to healthcare and diet- all of which also greatly affect human life expectancy.

For countries such as the United States, China, and France that experience different climates in different regions or states, the authors collected data about individual state/provincial climates and designated the titles 'mainly warm' or 'mainly cold' according to the mode or majority. For example, the United States comprises 50 states, out of which 29 experience marine, cold, or very cold climates and 21 experience mixed-dry and hot-humid climates. As a result of this majority, the authors classified the United States as 'mainly cold".

Figure 3 was drawn up using the Microsoft Excel software based on the number of regions around the world that were classified as warm and cold. Thereafter, mean life expectancies, standard deviation, minimum, and maximum values for each country were calculated based on the data made available from the United Nations World Mortality Report 2019. ${ }^{11}$ Tables 1 and 2 provide summaries for this data while Figure 6 paints a graphical representation.

To create Figure 5, the authors divided the world into twenty-two regions, irrespective of income groups. This was done to single out genetic factors and ethnicity, which too influence life expectancy. The twenty-two regions were then divided into warm and cold regions. The authors classified fifteen as warm and seven as cold. Their mean ages were then drawn up, once again using the United Nations World Mortality Report 2019. 11

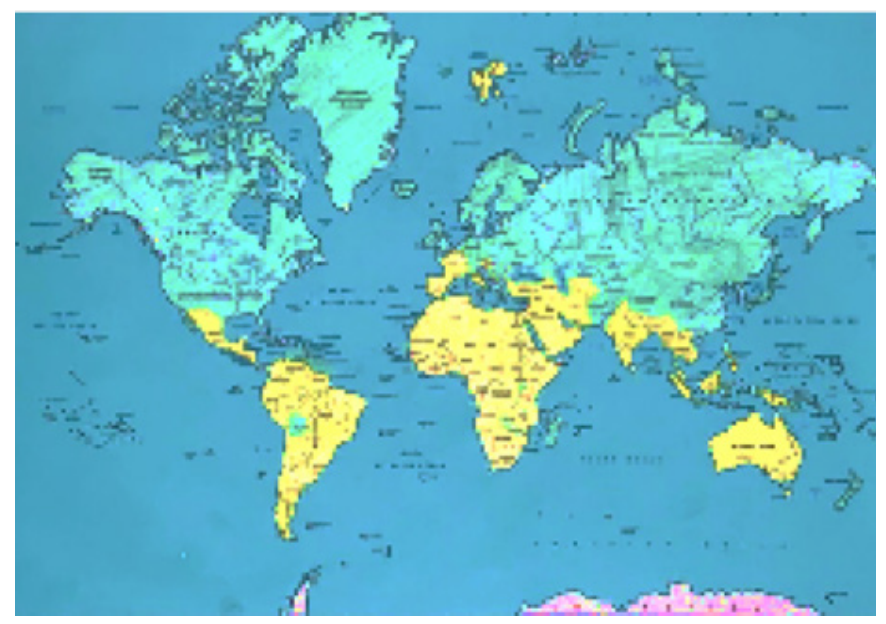

Figure 3: World map classified as warm and cold according to the authors' designed system. Key: warm is represented by yellow, cold by green and data not available as pink.

To calculate values for ANOVA, the authors used spreadsheet software Microsoft Excel to calculate the (X-mean $)^{2}$ value of each observation. The observations were mean life expectancies of each country listed on the United Nations World Mortality Report 2019. ${ }^{11}$ These observations were then divided into eight groups: warm socio-economic groups and cold socio-economic groups in accordance with the system described above. The sum of $(\mathrm{X} \text {-mean })^{2}$ was calculated for each group. Using this data, variance within each group, total sum of variance, variance within each group, degrees of freedom, F-value, and p-value were also calculated correspondingly using the formulas shown in Figure 4. The calculation was that standard to a typical ANOVA test.

\section{- Results and Discussion}

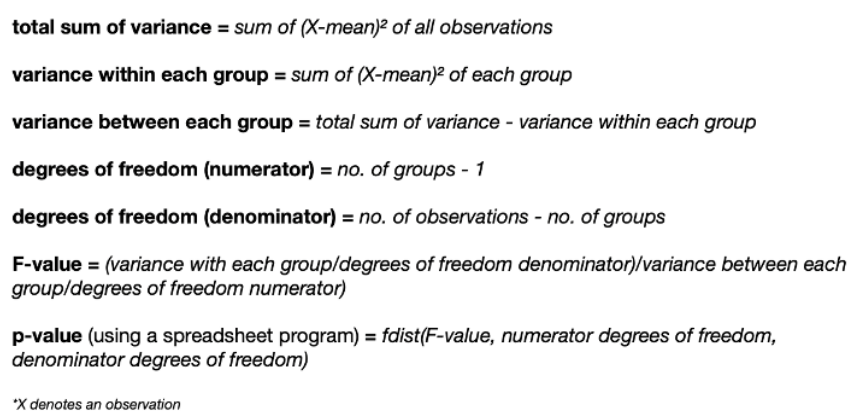

Figure 4: Formulas used while calculating ANOVA.

With global warming and a continuous increase in greenhouse gases over the decades, climate change has become a peril to mankind. Taking this as a motivation, the research report aims to find a clear link to rise in temperature and its direct effects on human life expectancy and longevity. The question of whether climate plays a quantifiable role in human longevity and life expectancy was tested by first classifying all countries according to income groups. Within these income groups, the countries were then further classified as 'mainly cold' and 'mainly warm' in order to mathematically measure the effects of climate and temperature. The means of ages and life expectancy were then calculated for each income group and cold and warm climates within those groups.

The pie chart is a representation of all the different regions around the world classified as 'mainly cold' or 'mainly warm'. The intent was to show the temperature distribution around the globe - with $33.8 \%$ being mainly cold regions and $66.2 \%$ being mainly warm regions (Figure 5).

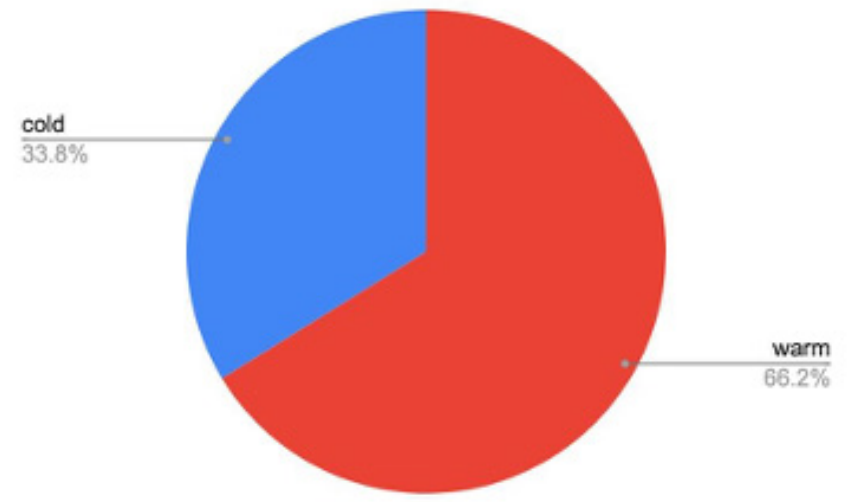

Figure 5: World region climates classified as percentages.

Across all income groups, the mean life expectancy was higher in the colder climates. With the lowest difference being between the lower-middle income groups, where colder climates displayed an average life expectancy that was 0.2371658 years higher than their warmer climate counterparts. The greatest difference was observed between the low-income groups where the average life expectancy differed by a large 
5.9098901 years in the colder climates compared to warmer ones. On average, the minimum life expectancy was higher in all income groups for the colder climate classification, except for the lower-middle-income group where they were almost equal. Additionally, the standard deviation for all income groups in the warmer climates was more spread out than the colder climates, suggesting that the warmer climate regions across all income groups saw a greater disparity in the ranges of life expectancy (Table 1, Table 2, Figure 6).

ANOVA, or analysis of variance, is a testing method to prove the statistical significance of the data collected. The main idea behind ANOVA is to determine how much of the variance comes between groups and how much comes from within groups. According to the calculated ANOVA test, the variance between each group (refer to Table 1 for grouped data) was more than double the variation within each group, which gives the authors a suggestion that climate does have a significant effect on life expectancy. To further test this, the authors calculated the F-value and p-value. The F-value of 49.88126711 is much larger than 1.0, while the p-value comes to exactly 0.00 and is less than 0.05 . The $\mathrm{p}$-value denotes that the probability of the null hypothesis taking place is $0 \%$ and the large $\mathrm{F}$-value means that variation within each group is more than what could be expected of chance. Together these values indicate strong evidence against the null hypothesis (climate doesn't affect human life expectancy) and accepts the alternative hypothesis (climate does play a role in human life expectancy), while proving the results statistically significant (Table 3).

Table 1: Summarized statistics of data for warm climate longevity. Data Sources for life expectancy: United Nations World Mortality Report 2019.11

\begin{tabular}{|c|c|c|c|c|}
\hline Warne Climate Langerity & mean & std.dev & $\min$ & $\max$ \\
\hline hight income & 79.4 & 3.372120994 & 735 & 83.6 \\
\hline upper-middke income & 73.68648649 & 4.876540336 & 58.7 & 80.3 \\
\hline lomer-middle income & 68.12647059 & 5.722645543 & 54.7 & 77 \\
\hline \begin{tabular}{|l|} 
len inceane \\
\end{tabular} & 62.16153646 & 4.460410467 & 533 & 66.6 \\
\hline
\end{tabular}

Table 2: Summarized statistics of data for cold climate longevity. Data Sources for life expectancy: United Nations World Mortality Report 2019. ${ }^{11}$

\begin{tabular}{|c|c|c|c|c|}
\hline Cold Climate Loszerity & mean & stdider & $\min$ & $\max$ \\
\hline bigh inteme & 8091481481 & 2.412579804 & 75.3 & 84.6 \\
\hline upper-middlie incame & 74.69 & 1.418485024 & 73 & 76.9 \\
\hline lower-mbidlle incerme & 69.06363636 & 560754362 & 543 & 73.8 \\
\hline bow income & 68.07142857 & 3.581457753 & 61.5 & 72.3 \\
\hline
\end{tabular}

Table 3: Data calculated for ANOVA

\begin{tabular}{|l|r|}
\hline Total Sum of Variance & 10055.85444 \\
\hline Variance within each group & 3292.753773 \\
\hline Variance between each group & 6763.100667 \\
\hline & \\
\hline Degrees of Freedom: & 7 \\
\hline numerator & 170 \\
\hline denominator & \\
\hline & \\
\hline F-value & 0 \\
\hline p-value & 49.88126711 \\
\hline
\end{tabular}

droughts, flooding, extreme weather conditions, more infectious diseases spread by vectors, also possibly genetic changes

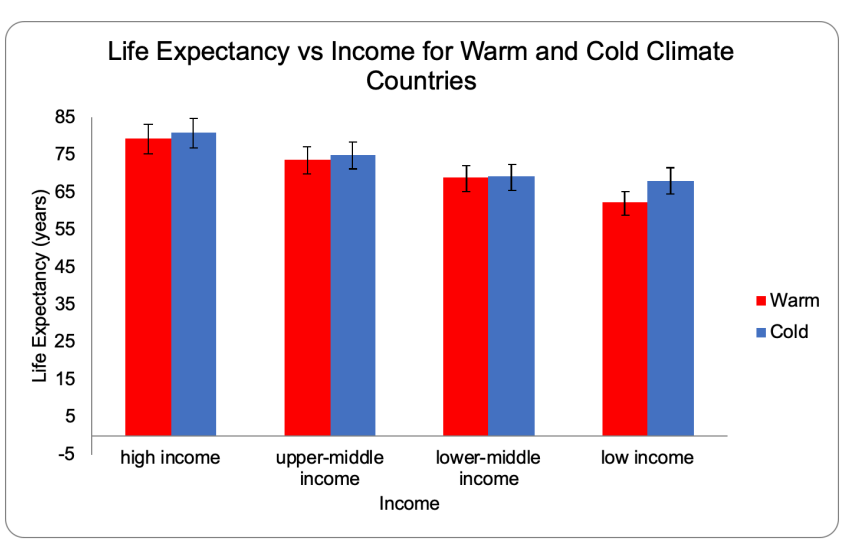

Figure 6: Tables 1 and 2 data represented graphically to show mean ages and data variation according to various income groups. Data Sources for income classification: United Nations World Economic Situation and Prospects 2019 Country Classification. ${ }^{12}$

The bar chart represents the mean life expectancy across 22 regions around the world that are further classified as 'mainly warm' (red) which comprises of 15 regions, and 'mainly cold' (blue) which accounts for the remaining 7. Upon examination, the highest life expectancy was found in Southern Europe (82.3 years), Western Europe (81.9 years) and Northern Europe (81.2 years). Within these three regions topping the list of life expectancy, two are classified as mainly cold. On the other hand, three mainly warm regions: Western Africa (57.9), Middle Africa (59.9) and Southern Africa (63.8) have the lowest life expectancies in the world (Figure 5).

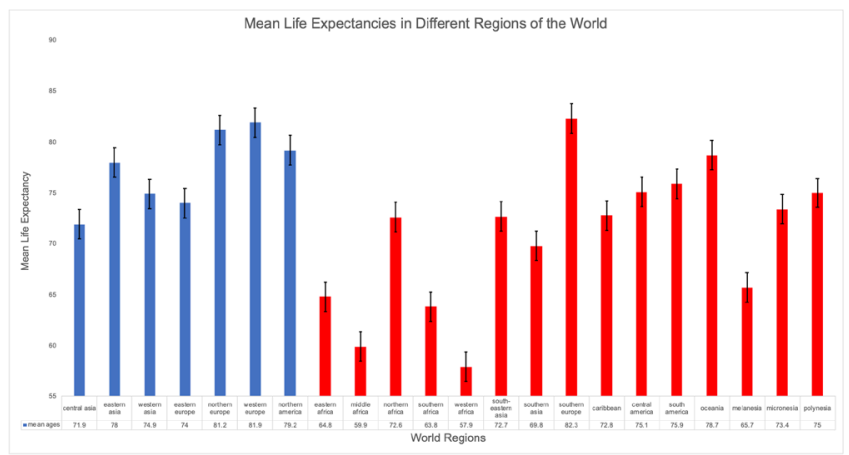

Figure 7: Mean life expectancies in different regions of the world. Blue bars illustrate colder regions, while red bars denote warm regions.

Data collected and examined from the research points towards the argument that human life expectancy can be extended by living in colder climates. Colder climates overwhelmingly display higher life expectancy in all four of the socio-economic country classifications.

All the data collected, recorded, and calculated showed average life expectancy to be higher in colder climates. Whether that difference was just 0.2371658 years higher in the case of lower-middle-income countries, or 5.9098901 years higher in the case of low income; the results indicate that living in colder climates can extend longevity. What can be concluded from this data is that climate change will have definite and lasting impacts on human life expectancy and lifespan. Rising and warmer temperatures will bring a lot of other complications to the table, including but not limited to famines, 
that could be triggered by these increasing temperatures - effects that no one knows or haven't yet been predicted.

According to the National Geographic, "Since 1906, the global average surface temperature has increased by more than 1.6 degrees Fahrenheit (0.9 degrees Celsius)". Scientists around the globe have already documented many drastic changes in the environment due to climate changes. Glaciers have contracted, ice on waterways and lakes is collapsing earlier, there have been peak rises in sea levels, intense and longer heat waves, plant and animal ranges have moved with many migrations noticed, and trees are blossoming sooner. ${ }^{13}$ Moreover, the World Health Organization (WHO) states that air pollution contributed by the emissions of fossil fuels as a result of the greenhouse effect, particularly sulfur and nitrogen-oxides can lead to respiratory diseases like asthma which can be seen in adults and children. It is stated that an estimated 7 million people die worldwide annually from air pollution. ${ }^{14}$

It is essential to stop climate change as it not only dramatically causes natural habitats to become isolated remnants, raises in sea levels, and increases extreme weather, but it also has a negative impact on human life and prosperity. For instance, the WHO has stated, "natural hazards like heat waves can burden health and emergency services and also increase strain on water, energy and transportation resulting in power shortages or even blackouts. Food and livelihood security may also be strained if people lose their crops or livestock due to extreme heat". ${ }^{15}$ Agriculture is one of the areas most affected, where farmers are bound to face attacks from weeds and pests which influence yield. Additionally, certain extreme events undermine crop yields. A study at the Bryan College of Health Science shows that the same $\mathrm{CO}_{2}$ amassing in our environment due to fossil fuels is altering the composition of legumes and fruits that we eat, making them less nutritious. ${ }^{16}$ Further increased $\mathrm{CO}_{2}$ is accelerating photosynthesis and making plants develop with more sugar and less calcium, protein, zinc, and other vital nutrients. Moreover, according to Harvard analysts, on the off chance that we don't diminish carbon emissions at the present time, this could spell a huge issue for our eating regimens. By the middle of the century around 175 million additional individuals have zinc insufficiency and 122 million individuals could become protein deficient because of these changes in plant physiology. This fundamental change in essential crops is a direct attack on our nutrition, which plays an elemental role in prolonging human life expectancy. ${ }^{17}$

The authors singled out income as a factor by classifying countries to yield constant and reliable results as far as possible. This is because income affects access to education, sanitation, healthcare, and diet, all of which play huge parts in extending or reducing human life expectancy. However, it is imperative to note that genetics, according to many scientists, plays an important role (about a third of variation in life expectancy is attributed to the genes: Apolipoprotein $\mathrm{E}$ (APOE), Forkhead box O3 (FOX03) and Cholesterylester transfer protein $(\mathrm{CETP}))^{18}$ in determining the expectancy of an individual and it acts as a limitation to the authors' study. While the authors did divide the world into different regions and study them separately, which allowed them to factor race and thus genetics to a degree, it still caused complications when developing valid results. Another source of bias could be the classification system of warm and cold climates allocated to each country - countries such as the United States of America and China see many different climates across their nation and while the authors classified it based on majority, it doesn't exclude the fact that discrepancies occurred. Japan is ranked as cold while Sardinia is as warm, but both are home to some of the oldest people around the world- this is due to their lifestyle factors which the authors accounted for when classifying data according to income groups, however, anomalies and variation do occur widely, such as in the case of Sardinia and Okinawa. The authors implore fellow scientists and researchers to conduct more trials to better determine the role of genetics irrespective of location and climate in affecting human life expectancy.

While conducting a thorough literature review of all the available studies on the topic of whether climate affects life expectancy, the authors came across multiple studies that further supported the results with concrete statistical and genetic evidence. A study conducted by economists from the Stanford University and the Massachusetts Institute of Technology in June 2019 collected extensive data over fifteen years of people who migrated after the age of 65 and those individuals who stayed in the same location their whole lives. This allowed them to factor out health, lifestyle, and genetics to isolate the effect of location on lifespan. The study found that life expectancy was lowest in the South of the United States (warmest parts of the country), and highest through the Upper Midwest (a much colder region). ${ }^{19}$ Additionally, according to researchers from the University of Michigan, worms that were introduced to colder temperatures triggered a genetic response that led to longer lifespans. The researchers believed that the probability of translating the same findings to humans is high since human beings have similar genetics. ${ }^{20}$ Following the same line of research, scientists at Scripps Research Institute in California reduced the internal body temperatures of warm-blooded animals like mice and found that this extended their lifespans by a substantial 20.0 percent. $^{21}$ This is corroborating evidence to the study and falls in with the quantitative measured results. Finally, when addressing climate change, researchers at the National Institute of Environmental Health Sciences found that an increase of 1 degree Celsius in temperature, increased the death rate for elderly between 2.8 and 4.0 percent. ${ }^{22}$ This is consistent with the findings, when the authors say that it is crucial to act now and reduce global temperatures.

The authors recognize individuals cannot move to colder geographic locations to theoretically increase the time they spend on this Earth. This is why the authors thought it vital to mention cold showers and cryotherapy. Most experiments that favor the effects of colder temperatures to increase life expectancy credit the explanation to either the free radical theory, or the fact that colder temperatures trigger genetic changes as observed in the study conducted at the University of Michigan. In such a case, taking cold showers or partaking 
in cryotherapy regularly could trigger changes in the genetic pathways over the long term that could allow an individual in a warmer climate to enjoy the same benefits their counterparts living in geographically colder climates do.

\section{- Conclusion}

It is clear from all data collected and quantified that individuals living in colder climates house longer-living individuals than their warmer climate counterparts. On average, when calculating the means of all life expectancies across all climate classifications and income groups, an individual may live an additional of 2.2163 years in colder regions while discrediting the role and involvement of genetics. The effects of climate change and warming of the Earth will therefore result in lower life expectancy. Further research and examination on the genetic impact of humans in different geographic locations would contribute meaningfully to this experiment. In addition, investigation of cryonics to extend the longevity of mankind, as well as preserve it can give this study a stronger grounding. Data collected and examined from research points towards the argument that human life expectancy can be extended by living in colder climates. Colder climates overwhelmingly display higher life expectancy in all four socio-economic country classifications.

\section{Acknowledgements}

The authors would like to thank their parents for the constant support, and motivation and thank biology teachers: Mrs. Usha Devi and Mrs. Nandini Sreekumar for their valuable feedback and guidance when making the final edits to the paper.

\section{- References}

1. "Life Expectancy at Birth." Charting the Progress of Populations, United Nations, 2000, pp. 45-49.

2. Mandal, Dr. Ananya. "Life Expectancy Versus Lifespan.” Nerws, 27 Feb. 2019, www.news-medical. net/health/Life-Expectancy-Versus-Life-Span.aspx.

3. Angel, J. Lawrence. "The Bases of Paleodemography." Wiley Online Library, John Wiley \& Sons, Ltd, 2 June 2005, onlinelibrary.wiley.com/doi/abs/ 10.1002/ajpa.1330300314.

4. "Life Expectancy." World Health Organization, World Health Organization, 15 May 2018, www.who.int/gho/mortality_burden_disease/life_ tables/situation_trends_text/en/.

5. "World Population Prospects: The 2017 Revision | Multimedia Library - United Nations Department of Economic and Social Affairs." United Nations, United Nations, 2017, www.un.org/development/desa/publications/worldpopulation-prospects-the-2017-revision.

6. 5 "Blue Zones" Where the World's Healthiest People Live, 10 Apr. 2017, www.nationalgeographic. $\mathrm{com} /$ books/features/5-blue-zones-where-theworlds-healthiest-people-live/.

7. "The Health Benefits of Living in a Warm Climate." Britannia Movers International, 27 May 2016, www.britannia-movers.co.uk/emigration-blog/healthbenefits-living-warm-climate.

8. Hatfield, Dolph L. "Redox Pioneer: Professor Vadim N. Gladyshev." Antioxidants E Redox Signaling, vol. 25, no. 1, 2016, pp. 1-9., doi:10.1089/ars.2015.6625.

9. Ognibene, Alex. Blue Zones. 16 Aug. 2019.

10.International Actuarial Association, 2017, Climate Change and Mortality.

11. United Nations, Department of Economic and Social Affairs, Population Division (2019). World Mortality 2019: Data Booklet (ST/ ESA/SER.A/436).

12. “Country Classification.” United Nations, 2019, www.un.org/development/desa/dpad/wp-content/ uploads/sites/45/WESP2019_BOOK-ANNEX-en.pdf.

13. "Global Warming Effects." Global Warming and Climate Change Effects: Information and Facts, 4 Feb. 2019, www.nationalgeographic.com/ environment/global-warming/global-warming-effects/.

14. Campbell-Lendrum, Diarmid, and Annette PrüssUstün. "Climate Change, Air Pollution and Noncommunicable Diseases." World Health Organization, World Health Organization, 31 Jan. 2019, www.who.int/bulletin/volumes/97/2/18-224295/en/.

15. "Heatwaves." World Health Organization, World Health Organization, www.who.int/health topics/heatwaves.

16.O'Brien, Jane. "Rising CO2 Is Making Food Less Nutritious "Yale Climate Connections." Yale Climate Connections, 16 Feb. 2018, www.yaleclimateconnections.org/2018/02/rising-co2is making-food-less-nutritious/.

17. Beach, Robert, et al. Elsevier Ltd, 2019, pp. 1-11, Combining the Effects of Increased Atmospheric Carbon Dioxide on Protein, Iron, and Zinc Availability and Projected Climate Change on Global Diets: a Modelling Study.

18. "Is Longevity Determined by Genetics? - Genetics Home Reference - NIH.” U.S. National Library of Medicine, National Institutes of Health, 7 July 2020, ghr.nlm.nih.gov/primer/traits/longevity.

19. Finkelstein, Amy, et al. 2019, pp. 1-74, PLACEBASED DRIVERS OF MORTALITY: EVIDENCE FROM MIGRATION.

20. Xiao, Rui. Cell Journal, 2015, pp. 1-12, A Genetic Program Promotes C. Elegans Longevity at Cold Temperatures via a Thermosensitive TRP Channel.

21.Conti, Bruno. "New Research Reveals Pathway for Anti-Aging Therapies." New Research Reveals Pathway for Anti-Aging Therapies | Scripps Research, 2017.

22. "Is Longevity Determined by Genetics? Genetics Home Reference - NIH."U.S. National Library of Medicine, National Institutes of Health, 7 July 2020, ghr.nlm.nih.gov/primer/traits/longevity.

\section{Author}

Riya Kewalani was born in 2002 in Moscow and is a graduate of Dubai Gem Private School. Kewalani is highly passionate about human biology, the climate crisis and medical ethics. She hopes to pursue medicine with biological research, and provide a valuable and positive contribution to society. Kewalani also is the co-founder of Dubai Gem Podcasts, designed to inform, inspire and ignite conversations among the youth. 
Insiya Saifudeen is a senior at Dubai Gem Private School and is currently studying A-level Maths, Chemistry and Biology. She is an avid swimmer, horse-rider,basket-ball player, guitarist and a linguist. Her main drive to write this research report was to investigate climate change and highlight it to be a reality. She is the co-founder of Sahaa, a virtual platform, where she educates and raises awareness on diseases and healthy living. Insiya aspires to integrate her love for science with her interest in research, while she pursues a career in medicine, to find innovate solutions to global issues. 